\title{
INDICAÇÕES BIBLIOGRÁFICAS
}

\section{Gestão de empresas de serviços profissionais}

Marcelo P. Binder | marcelo.binder@fgv.br

As empresas de serviços profissionais são pouco estudadas no Brasil, mas atraem interesse de pesquisadores há algum tempo no exterior, existindo até uma sigla para delimitar o setor professional service firm (PSF). Esse tipo de empresa envolve a prestação de um serviço pessoal e de conteúdo técnico (advocacia, consultoria, publicidade etc.). Por isso, muitos conceitos desenvolvidos para empresas industriais ou mesmo de serviços tradicionais, como varejo, não se aplicam às PSFs. Pesquisando essa temática, o professor Marcelo P. Binder (FGV-EAESP) sugere cinco referências de leitura. A maior parte dos livros é direcionada aos praticantes, possuem bom referencial teórico traduzindo teorias tradicionais e formulando novos conceitos para a realidade das empresas de serviços profissionais

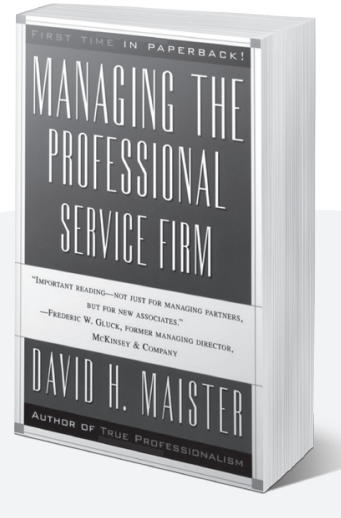

\section{MANAGING THE PROFESSIONAL SERVICE FIRM}

David H. Maister. New York: Free Press Paperbacks, 1997.384 p.

Este livro é considerado um "clássico" na gestão de serviços profissionais. Voltado para gestores, a obra apresenta os principais temas relacionados a serviços profissionais. Com este livro, o autor, ex-professor de Harvard, tornou-se uma referência na gestão de serviços, e seus modelos passaram a ser citados posteriormente por outros autores. Embora tenha escrito vários outros livros sobre o assunto, nenhum deles obteve o mesmo sucesso e alcance.

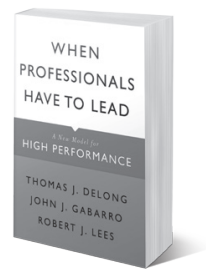

WHEN PROFESSIONALS HAVE TO LEAD: A new model for high performance

Thomas J. DeLong, John J. Gabarro e Robert J. Lees. Boston: Harvard BusinessSchool Press, 2007. 272 p.

O livro enfatiza aspectos críticos para o liderança de uma empresa de serviços profissionais: criar a direção estratégica, gerar e assegurar comprometimento com a direção criada, facilitar a execução e dar o exemplo pessoal. Os autores, além do trabalho acadêmico, ligado à Harvard Business School, possuem larga experiência prática no setor; assim, a obra é farta de exemplos sobre os impactos da teoria e recomendações de como aplicá-la.

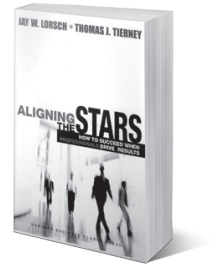

ALIGNING THE STARS: How to succeed when professionals drive results Jay W. Lorsch e Thomas J. Tierney. Boston: Harvard Business School Press 2002. 252 p.

Neste livro, um professor de Harvard e o ex-CEO da consultoria Bain \& Company analisam como empresas bem-sucedidas (de bancos de investimento a escritórios de advocacia) alinham seus talentos e, efetivamente, fazem a diferença em seus setores. Para eles, pessoas e, especialmente, talentos diferenciados são o coração de uma empresa de serviços profissionais. O livro é baseado em pesquisas e cheio de exemplos concretos de coisas que deram certo e deram errado.

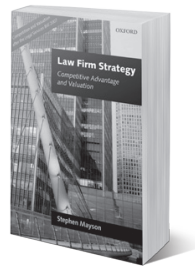

\section{LAW FIRM STRATEGY: Competitive advantage and valuation}

Stephen Mayson. New York: Oxford University, 2007. 250 p.

As empresas de serviços profissionais possuem similaridades, mas cada setor tem suas particularidades, em função da natureza do trabalho. Neste livro, o autor traz, com brilhantismo, as diferenças, características e nuances das firmas de advocacia, traduzindo, com profundidade e propriedade, conceitos teóricos de estratégia e gestão para a área jurídica. É um livro com boa fundamentação teórica e uma referência na prática na gestão de escritórios de advocacia.

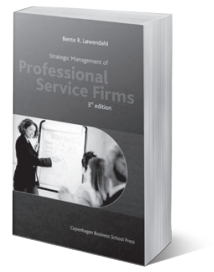

\section{STRATEGIC MANAGEMENT OF PROFESSIONAL SERVICE FIRMS}

Bente R. Lowendahl. Copenhagen: Copenhagen Business School, 2005. 219 p.

Diferentemente das outras obras indicadas, este livro tem seu foco na teoria. Ao contrário dos anteriores, escritos por praticantes com envolvimento acadêmico, a autora é uma acadêmica "pura", e o livro é fruto de seu doutorado em Wharton. Seu conteúdo é consistente, abordando com profundidade os temas relativos à estratégia para serviços profissionais, porém não apresenta os exemplos e frameworks tão apreciados pelos gestores de empresas. 